\title{
Activity-dependent modulation of neural circuit synaptic connectivity
}

\section{Charles R. Tessier and Kendal Broadie*}

Department of Biological Sciences, Vanderbilt University, Nashville, TN, USA

\section{Edited by:}

William Wisden, Imperial College, UK

Reviewed by:

James Hodge, University of Bristol, UK

Christoph Schuster, University of

Heidelberg, Germany

William Wisden, Imperial College, UK

\section{${ }^{*}$ Correspondence:}

Kendal Broadie, Department of

Biological Sciences, Vanderbilt

University, 6270 MRB III, 46521 st

Avenue, South Nashville,

TN 37232, USA.

e-mail:kendal.broadie@vanderbilt.edu
In many nervous systems, the establishment of neural circuits is known to proceed via a two-stage process; (1) early, activity-independent wiring to produce a rough map characterized by excessive synaptic connections, and (2) subsequent, use-dependent pruning to eliminate inappropriate connections and reinforce maintained synapses. In invertebrates, however, evidence of the activity-dependent phase of synaptic refinement has been elusive, and the dogma has long been that invertebrate circuits are "hard-wired" in a purely activity-independent manner. This conclusion has been challenged recently through the use of new transgenic tools employed in the powerful Drosophila system, which have allowed unprecedented temporal control and single neuron imaging resolution. These recent studies reveal that activity-dependent mechanisms are indeed required to refine circuit maps in Drosophila during precise, restricted windows of late-phase development. Such mechanisms of circuit refinement may be key to understanding a number of human neurological diseases, including developmental disorders such as Fragile $X$ syndrome (FXS) and autism, which are hypothesized to result from defects in synaptic connectivity and activity-dependent circuit function. This review focuses on our current understanding of activity-dependent synaptic connectivity in Drosophila, primarily through analyzing the role of the fragile X mental retardation protein (FMRP) in the Drosophila FXS disease model. The particular emphasis of this review is on the expanding array of new genetically-encoded tools that are allowing cellular events and molecular players to be dissected with ever greater precision and detail.

Keywords: neurotransmission, synapse, pruning, fragile X syndrome, FMRP, Drosophila, development

\section{INTRODUCTION}

The development of neural circuits is initiated with the "softwiring" of speculative synaptic connections that form the foundation of specific penultimate circuits, and culminates with a process of refinement in which the correct synaptic connections are solidified, while improper connections are systematically weakened and removed from the circuit. The initial phase of synaptic overgrowth is presumably required to ensure that the nervous system is completely wired in the proper manner without missing essential synaptic targets. It is hypothesized that a less inclusive, more precise growth, extension and connection program would run the risk of missing important synaptic connections and thus leave the brain with impaired processing capacity and unable to efficiently respond to the myriad of sensory demands from the environment. Moreover, the removal of inappropriate synapses, coupled to the addition of newly acquired synapses, provides a vital segregation mechanism to distinguish connections with common functionality. Thus, before so-called "hard-wiring" can be complete, circuits must go through a period of neuronal process pruning.

The refinement of neural circuitry depends on a period of neuronal activity, which is known to be necessary for the final specification of the synaptic map. This activity-dependent process has been classically investigated in the vertebrate neuromusculature and visual sensory system, with less exploration in higher order central brain integration circuits (Cang et al., 2005b; Chandrasekaran et al., 2005; Liu et al., 1994; Wiesel, 1982). In these systems, an early soft-wiring program of activity-independent mechanisms involving guidance cues, diffusible signaling ligands and transmembrane receptors appears sufficient to direct pre- and postsynaptic processes to proper locations and culminate in synaptogenesis (Cang et al., 2005a; Cutforth et al., 2003; Feinstein and Mombaerts, 2004; Feinstein et al., 2004; Imai et al., 2006; Yates et al., 2001). The final refinement of both dendritic and axonal projections to specify the mature synaptic map then requires intrinsic synaptic firing (for review see Wong and Ghosh, 2002). In some circuits, such as the mammalian olfactory system, the relative role of activity-dependent refinement is more controversial, as different groups have found evidence for and against this process (Lin et al., 2000; Marks et al., 2006; Yu et al., 2004; Zheng et al., 2000).

In invertebrates, the involvement of synaptic activity in modulating circuits is much less clear. The dogma has long been that invertebrate circuits are hard-wired from the early stages of development, and do not employ activity-dependent refinement in a manner comparable to vertebrates. Indeed, a strong body of experimental evidence supports this position, in both primary sensory circuits and higher order systems (Berdnik et al., 2006; Hiesinger et al., 2006; Jefferis et al., 2004; Oland et al., 1996; Scott et al., 2003; Srahna et al., 2006). However, both classical and recent evidence has shown that environmental experience in invertebrates is capable of modulating the connectivity of sensory and higher order circuits 
(Chiba et al., 1988; Devaud et al., 2001, 2003; Fahrbach et al., 1995; Sachse et al., 2007; Withers et al., 1993). Very recently, detailed structural analysis of single neuron architecture in vivo has shown activity-dependent refinement of circuits as a late-occurring phase of development (Tessier and Broadie, 2008; Tripodi et al., 2008). These new insights have resulted from advances in the powerful Drosophila genetic system, and novel transgenic tools position a field now poised to dissect the cellular and molecular mechanisms of circuit map refinement.

Multiple neurological disorders of mental retardation and autism likely arise from defects in neural circuit refinement. The most common of these is Fragile X syndrome (FXS), an X-linked inherited genetic disorder of mental retardation (IQ < 40), autism and hyperexcitability (Cohen et al., 2005; Hagerman et al., 2005; Rogers et al., 2001; Sullivan et al., 2006). FXS patients commonly exhibit hypersensitivity to sensory stimuli, hyperactivity and attention deficit disorder, with approximately $20 \%$ of patients manifesting epileptic seizures during childhood (Berry-Kravis, 2002; Incorpora et al., 2002; Musumeci et al., 1999). A great deal of recent interest has focused on FXS at the intersection of developmental circuit refinement and neuronal activation. FXS is caused by loss of function of the fragile X mental retardation (FMR1) gene, a member of a tripartite gene family (Pieretti et al., 1991; Siomi et al., 1995; Zhang et al., 1995). In rodents, the expression and function of the FMR1 product (FMRP) is regulated by neuronal activity levels, with the FMRP expression peak during the early postnatal period of synaptic refinement (Ferrari et al., 2007; Khandjian et al., 1995; Ostroff et al., 2002; Singh et al., 2007; Tessier and Broadie, 2008; Wang et al., 2004, 2008). A hallmark of FMRP loss is the failure to remove immature synaptic connections (Comery et al., 1997; Galvez and Greenough, 2005; Galvez et al., 2003, 2005; Irwin et al., 2001, 2002; McKinney et al., 2005; Nimchinsky et al., 2001; Rudelli et al., 1985). Thus, FMRP is a leading candidate for a molecule mediating activity-dependent synaptic refinement.

A powerful FXS model has been long established in Drosophila (Wan et al., 2000; Zhang et al., 2001). There is only a single homologous Drosophila FMR1 gene $(d f m r 1)$, so its deletion is presumably more comparable to loss of the tripartite gene family in mammals. Consistently, null $d f m r 1$ mutants exhibit strikingly similar molecular, cellular and behavioral phenotypes compared to mouse FMR1 knockouts, but with the great advantage of increased robustness of phenotype manifestation (Zhang and Broadie, 2005). A particular advantage of the Drosophila model is the UAS-GAL4 promoter/ transcriptional activator transgenic tools which permit spatially and temporally targeted genetic manipulation of this system (Fischer et al., 1988). For example, transgenic expression of modified ion channels can be used to potentiate or depress neuronal function to probe roles of neuronal activity in identified circuits, and transgenic reporters can be similarly introduced to monitor this activity (Mosca et al., 2005; Reiff et al., 2005; White et al., 2001). The Mosaic Analysis with a Repressible Cell Marker (MARCM) clonal approach permits such manipulation down to the level of single neurons within defined circuits (Lee and Luo, 2001). The inducible GeneSwitch system can control these tools at specific temporal or developmental time windows (Osterwalder et al., 2001). The vast array of targeted activator lines available allows interrogation of relevant circuitry throughout the fly brain.
This review focuses on recent work in the Drosophila FXS model showing that activity-dependent refinement of synaptic architecture in defined brain circuits proceeds into the adult stage of the life cycle. The many genetic tools being used to dissect the roles of the critical FMRP synaptic regulator will be discussed. In this review, we distinguish between early activity-dependent refinement of synaptic connections and maintained activity-dependent synaptic plasticity. Developmental refinement includes architectural and functional remodeling of a circuit in response to initial-use neuronal activity, which is necessary to sculpt the final synaptic map. This mechanism is restricted to precise developmental windows corresponding to activation by external experience. In contrast, synaptic plasticity involves activity-dependent alterations in synaptic structure and function required for the generation of higher order brain activities, such as learning and memory. This is a maintained property of neuronal circuits, which is temporally separable. However, it may be that the developmental refinement sets the stage to permit the plastic modulations later in life, or that these two activity-dependent processes may involve an overlapping cast of molecular players.

\section{DEVELOPMENTAL WINDOWS OF ACTIVITY-DEPENDENT CIRCUIT MODULATION}

Sensory systems are particularly attractive for the study of activitydependent development, owing to the stereotypic structuring of sensory neurons and the ease of manipulating appropriate activity input. In the Drosophila visual system (Figure 1A), the dogma has been that development proceeds solely via intrinsic genetic elements such as receptor/ligand interactions, and specifically that neuronal activity is not required for the final hard-wired map to form. For example, blocking visual activity by dark-rearing animals reportedly caused no clear changes in dendritic structure in the lamina (Scott et al., 2003). A more rigorous experiment using the UAS/ GAL4 system to express the cell death head involution defective ( hid) gene to destroy photoreceptors in the imaginal discs as soon as they are born, similarly failed to detect significant alterations in
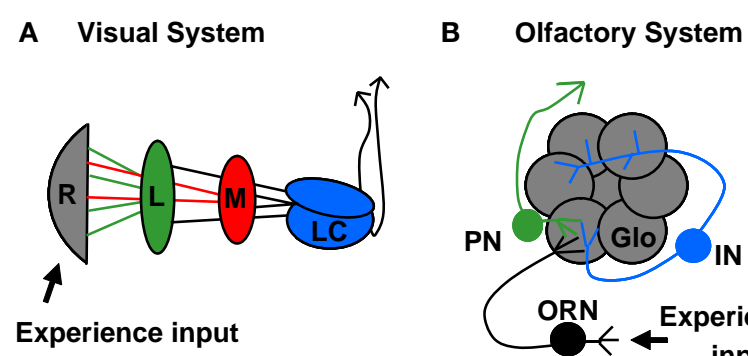

FIGURE 1 | Organization of Drosophila olfactory and visual systems. (A) The visual lobe receives input from retinal photoreceptor cells (grey). Photoreceptors 1-6 project to the lamina neuropil (green) while photoreceptors 7 and 8 project to the medulla neuropil (red). Signals are further processed in the lobula complex (blue) before proceeding to higher order brain regions. (B) The olfactory system receives input from olfactory sensory neurons (black), which each project axons to unique olfactory lobe glomeruli (grey). Local interneurons (blue) process information from multiple glomeruli. Projection neurons (green) transmit signals to higher order brain regions, including the Mushroom Body. 
laminal dendritic structures (Scott et al., 2003). Likewise, a large scale high-resolution electron microscopy study revealed no differences in synapse number, or the location of synaptic boutons, in photoreceptor contacts from 43 different genetic mutants altering the levels of synaptic activity (Hiesinger et al., 2006). These studies therefore concluded that neuronal activity is not required for circuit map refinement. Similarly, the Drosophila olfactory system is reportedly largely stable throughout pupal morphogenesis (Figure 1B), and olfactory lobe innervations by either the pre- or postsynaptic cell are still patterned in the absence of the opposing synaptic partner (Berdnik et al., 2006). In contrast, serotonergic interneurons in the Drosophila antennal lobe display dramatic reorganization throughout development, which is dependent on evoked and spontaneous neural activity (Roy et al., 2007). It is important to note that the Drosophila studies have all focused on developmental time points during pupal metamorphosis, as circuit activity has been shown to be functioning during this developmental transition (Hardie et al., 1993). However, it is not clear when the development of these circuits ends and a "mature state" is achieved. The moment when the insect emerges from the pupal case (eclosion), is commonly considered the end of development and the start of adulthood, without any defined transitory period. This delineation appears as naïve as considering birth to be the end of development in mammals: the postnatal period is the active stage of activity-dependent refinement and synapse elimination. Similarly, changes in the volume of Drosophila olfactory glomeruli and visual lamina occur within days after eclosion (Barth et al., 1997; Devaud et al., 2001, 2003; Sachse et al., 2007). Recent work in both flies and ants has shown pruning of axonal processes, dendrites and synaptic connections occurs during the post-eclosion period (Seid and Wehner, 2009; Tessier and Broadie, 2008). Thus, during the initial early-use period following eclosion, Drosophila shows developmental refinement of synaptic processes, which we believe will become increasingly apparent with advances in genetic tools and high-resolution imaging.

The fragile $\mathrm{X}$ mental retardation protein (FMRP) appears to be one player modulating the refinement of synaptic processes. FMRP is an mRNA-binding protein implicated in transcript stability, transport and translational repression (for review, see Bassell and Warren, 2008). A popular hypothesis is that FMRP represses mRNA translation during transport to synapses and locally modulates translation in response to synaptic activity. In this mechanism, FMRP provides the means of ensuring that proteins required for synaptic structure and function are efficiently translated in response to use-dependent need. Importantly, FMRP expression peaks sharply during the developmental period of synaptic refinement, both in vertebrates and invertebrates, which suggests a predominant role in this transitory mechanism. In Drosophila, dFMRP is strongly expressed in the brain during late stages of pupal metamorphosis and shortly after eclosion (Tessier and Broadie, 2008). Following the early-use period, dFMRP protein levels drops precipitously to a low level, which is thereafter maintained throughout adulthood. Interestingly, the $d f m r 1$ mRNA profile mimics the dFMRP protein levels throughout development, but then diverges in the adult animal when $d f m r l$ transcript levels rise to high levels but the dFMRP protein remains scarce (Tessier and Broadie, 2008). This suggests two distinct mechanisms of dFMRP regulation during (1) the post-eclosion refinement period and (2) presumed synaptic plasticity mechanisms in the mature animal. Further support for a transient role of dFMRP is apparent in the earlier larval period of development (Gatto and Broadie, 2008). The conditional GeneSwitch system was used to control the temporal expression of dFMRP in the nervous system (Osterwalder et al., 2001). GeneSwitch is a pharmacologically controlled version of the UAS-GAL4 system in which the GAL4 activator protein requires the cofactor RU486 (an analog of mifepristone) to promote transcription at UAS promoter sites. The drug may be mixed with standard fly food, or applied topically to induce targeted gene transcription. After removal of the drug, expression of the UAS transgene once again stops. Thus, the GeneSwitch system adds temporal control of gene expression to the inherent spatial control of the classical UAS-GAL4 method. Conditional dFMRP expression in $\mathrm{dfmr} 1$ null animals is effective in reducing synaptic defects only when the induction window is during the early-use period immediately after larval hatching (Gatto and Broadie, 2008). Late dFMRP induction at maturity only very weakly alleviates a subset of synaptic defects. Thus, dFMRP peak expression and functional requirement both correspond to the restricted developmental windows of early use refinement.

Several lines of evidence suggest that FMRP functions directly downstream of neuronal activity (reviewed in Bassell and Warren, 2008). FMRP associates with polyribosomes in an activitydependent manner and phosphorylated FMRP functions to locally repress the translation of critical synaptic proteins. After activation, FMRP is rapidly dephosphorylated to relieve this repression, but is subsequently re-phosphorylated to prevent excessive translation. In rodents, FMRP expression itself is regulated by sensory input activity (Irwin et al., 2005; Todd and Mack, 2000). Similarly in Drosophila, rearing in sensory deprived conditions results in decreased levels of both $d f m r 1 \mathrm{mRNA}$ and dFMRP protein in the brain (Tessier and Broadie, 2008). Likewise, dFMRP expression is significantly reduced in mutant animals with genetic blocks in olfactory and visual sensory pathways. Importantly, this activitydependent regulation occurs during the period of early circuit usedependent refinement, when dFMRP levels are transiently elevated compared with the mature animal (Tessier and Broadie, 2008). Thus, it is probable that dFMRP is acting as a monitor of circuit activity during this time window, with its expression controlled by sensory input and activity-dependent processes regulated by the translation of subsets of synaptic mRNAs.

The translation of many FMRP mRNA targets (e.g. MAP1B, Arc/Arg3.1 and PSD95) is rapidly upregulated by synaptic activation of metabotropic glutamate receptors (mGluRs), (Davidkova and Carroll, 2007; Park et al., 2008; Todd et al., 2003; Waung et al., 2008). The overextension of synaptic complexity in FMR1 knockout mice can be rescued either by antagonizing mGluR signaling or by more broadly enriching environmental stimulation (de Vrij et al., 2008; Restivo et al., 2005). The latter is also effective at eliminating hyperactive behaviors in FMR1 mutant mice (Restivo et al., 2005). Together, these studies suggest that FMR1 mutant animals exist in a state of heightened activity, which therefore precludes cellular responses to additional input. In the Drosophila FXS model, the translation of the dFMRP mRNA targets (e.g. chickadee/profilin) is elevated in genetic mutants blocking sensory activity inputs 
(Tessier and Broadie, 2008). To examine structural consequences of functional cell-autonomous requirements, Mosaic Analysis with a Repressible Cell Marker (MARCM) can be used to visualize single mutant neurons in an otherwise wildtype brain (Figure 2). This genetic technique might be compared to Golgi staining, with the important addition that neurons labeled via MARCM are mutant for the gene of interest while all unlabeled neurons remain unaffected. The MARCM method uses a GAL4 activator expressed in a subset of neurons to turn on expression of a UAS-promoter controlled GFP transgene (Lee and Luo, 2001). However, the animals also ubiquitously express a GAL80 repressor, which inhibits GAL4 activation. To alleviate this repression, a heat shock controlled flipase is used to induce mitotic recombination between targeted FRT sites on the chromosome carrying the GAL80 repressor and the chromosome carrying the mutant gene of interest (in this case, $d f m r 1$ ). By timing the recombination to coincide with the development of a known neuronal population, the result is a mutant clone lacking the GAL80 repressor. Thus, GFP is expressed, effectively labeling the mutant clonal population and permitting mutant cell structural analyses. The Drosophila Mushroom Body (MB) learning/memory center is critical for the integration of sensory experience (Figure 2A). MARCM analysis of single MB neurons (Figure 2B), comparing control to $d f m r 1$ mutant cells, revealed structural over-elaboration of synaptic connections, both in axonal processes and dendritic arbors (Pan et al., 2004). By definition, this requirement is cell-autonomous and also bidirectional, since

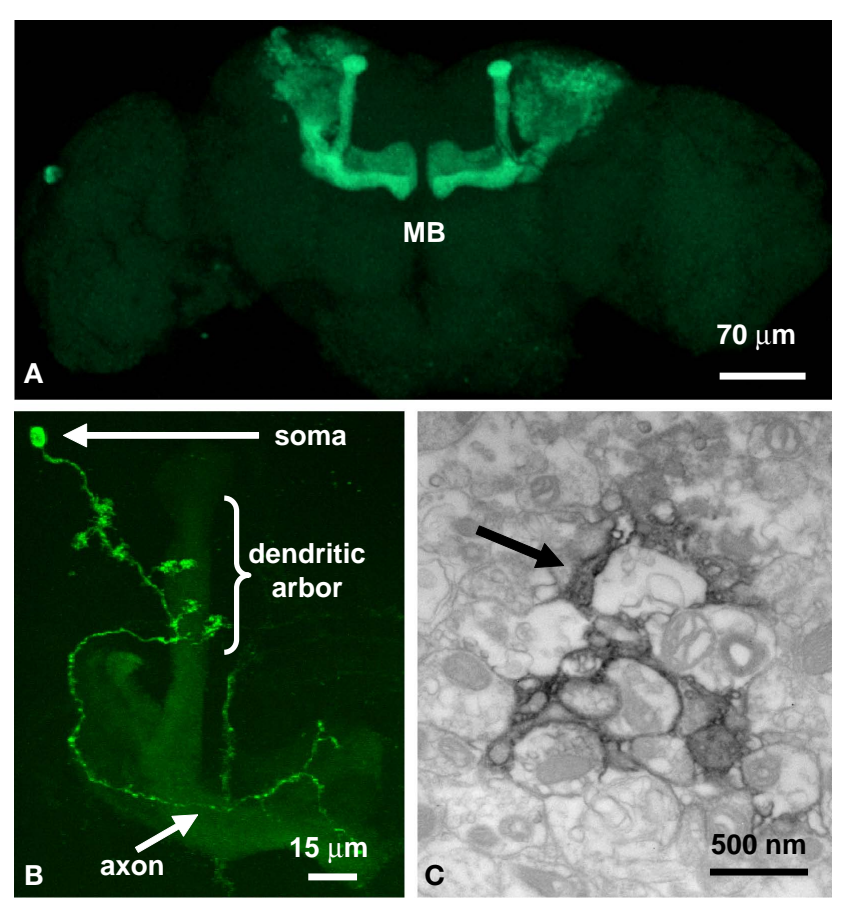

FIGURE 2 | Imaging the mushroom body learning and memory center. (A) OK107-GAL4 line driving GFP in the Mushroom Body (MB). (B) A single MB neuron clone generated by MARCM. (C) The MARCM fluorescent signal photoconverted to an electron-dense signal in the presence of diaminobenzene (DAB) with high intensity $490 \mathrm{~nm}$ light. The arrow points to a labeled MB process.
dFMRP over-expression greatly reduced the number of synaptic connections. The fluorescent GFP signal from MARCM clones was then photoconverted to an electron-dense signal for ultrastructural analyses (Figure 2C). This powerful method showed that synaptic differentiation was altered in the absence of dFMRP, with a loss of regulation in synaptic bouton size and establishing synaptic vesicle pools (Pan et al., 2004). These MARCM defects were reversed by pharmacologically antagonizing mGluRs with 2-methyl-6(phenylethynyl)-pyridine (MPEP), showing that dFMRP functions to control synaptic connectivity via a pathway mediated by synaptic mGluR activity (Pan et al., 2008). It was subsequently established that an axonal pruning and synapse elimination program in these $\mathrm{MB}$ neurons normally occurs shortly after eclosion, during the initial use period, and that this refinement mechanism is lost in $d f m r 1$ null neurons during this specific developmental window (Tessier and Broadie, 2008).

A recently developed means of directly manipulating neuronal activity in vivo employs the UAS-GAL4 system to target expression of a Chlamydemonas light-gated ion channel, channelopsin (Boyden et al., 2005; Nagel et al., 2003; Schroll et al., 2006). In the presence of the cofactor, all-trans retinal, this exogenous channel, referred to as channelrhodopsin (CHR2), conducts depolarizing current when stimulated with $480 \mathrm{nM}$ blue light (reviewed in this issue). In Drosophila, this technique has recently been used broadly to control the activity of selected subsets of neurons by targeting UAS-CHR2 expression with a range of GAL4 driver lines (Borue et al., 2009; Hornstein et al., 2009; Pulver et al., 2009; Zhang et al., 2007). In addition to the targeting advantages, the electrophysiological functioning of the channel is now being manipulated, which will permit even more precise control of synaptic events (Nikolic et al., 2009; Radu et al., 2009; Wang et al., 2009a). When targeted to MB neurons, activation of the CHR2 channel effectively augmented activity-dependent synaptic pruning in control animals, but completely failed to do so in $d f m r 1$ null animals (Tessier and Broadie, 2008). This pruning function was restricted to the early-use developmental window in post-eclosion animals; reintroduction of environmental stimulation in mature animals failed to induce pruning. Thus, precise timing of events must be required for the activity-dependent pruning mechanism of dFMRP function, further suggesting that dFMRP itself may be the specific molecule "reading" the activity input required for refinement of neuronal circuits.

More generally, developing Drosophila neurons have also been recently imaged in genetic mutants that either lack the ability to produce neurotransmitter, or were targeted with the UAS-GAL4 system to express tetanus light chain toxin (TNT-LC) to eliminate neurotransmitter release (Tripodi et al., 2008). The TNT-LC protease cleaves the integral synaptic vesicle protein $n$-synaptobrevin in the presynaptic terminal and thereby eliminates evoked, but not spontaneous, neurotransmitter release (Broadie et al., 1995; Sweeney et al., 1995). This transgenic tool provides an excellent means of ascertaining cellular responses and developmental requirements of evoked neurotransmission. Earlier studies have clearly shown that the synaptic outputs of motor neurons at the neuromuscular junction (NMJ), are sculpted by activity at multiple levels of structural and functional refinement (Broadie and Bate, 1993; Budnik et al., 1990; Jarecki and Keshishian, 1995; Mosca 
et al., 2005). In a recent study on embryonic motor neurons, it was determined that the elongation of dendritic branches onto which silenced synapses input was mitigated simply by the act of contact between the pre- and postsynaptic cell, and was independent of synaptic activity (Tripodi et al., 2008). However, presynaptic activity was required for synaptic refinement, as neurotransmission was involved in regulating local dendritic architecture. Blocking evoked transmission with TNT-LC resulted in an increase in the length of dendritic branches which did not themselves make synaptic contacts, but were derived from the same ordered branch as a branch which did make a synaptic contact (Tripodi et al., 2008). Thus, the growth of these so-called "non-synaptic sister branches" was locally controlled by nearby synaptic activity. This study further suggested that global changes in dendritic structure may be used to compensate for alterations in synaptic input. In other words, if the postsynaptic cell does not receive the correct amount of presynaptic input, it can elaborate its dendritic arbor to ensure proper synaptic coverage. These intriguing findings show that the arrangement of the final synaptic systems in the Drosophila neuromusculature involve activity-dependent mechanisms.

\section{LEVELS OF ACTIVITY CONTROL}

Neurotransmitter-activated G-protein coupled receptors participate in neurotransmission via G-protein dependent downstream signaling cascades (Conn and Pin, 1997). The role of metabotropic glutamate receptors (mGluRs) in particular has been well documented in regulating both synaptic architecture and function. In mammals, these receptors are divided into 3 classes of 8 subtypes (Pin and Duvoisin, 1995), with marked distribution and functional differences. Group I mGluR5 functions upstream of FMRP, and FMRP functions in mGluR-induced forms of synaptic plasticity (Hou et al., 2006; Nosyreva and Huber, 2006; Wilson and Cox, 2007; Zhang et al., 2009). The mGluR (or Gq) theory of Fragile X proposes that synaptic Gq signaling through such receptors regulates FMRP to control the translation of specific mRNAs modulating synapse structure and function (Bear et al., 2004; Volk et al., 2007). However, the application of this theory to neural circuit development is not clear. In support of such a developmental model, mGluR5 is important for synaptic development, although this role may be region-specific (Hannan et al., 2001). For example, recent studies show that formation of the mouse somatosensory barrel cortex is dependent on mGluR5, with knockout mice exhibiting a nearly complete loss of barrel segregation in developing layer 4 neurons (Wijetunge et al., 2008). Mutant neurons exhibit a reduced density of dendritic spines. In contrast, no difference was seen in dendritic spines from mGlur5+/- heterozygote layer 3 pyramidal neurons (Dolen et al., 2007). Consistently, expression pattern analysis and pharmacological disruption of mGluR signaling demonstrates these receptors function differentially during development and at maturity to regulate differentiation of dendritic spines as well as mediate synaptic plasticity (Chen and Roper, 2004; Doherty et al., 2004; Mares, 2009; Mateo and Porter, 2007; Reid and Romano, 2001; Reid et al., 1997; Vanderklish and Edelman, 2002; Wang et al., 2007). Since FMRP functions downstream of mGluR signaling, and is itself developmentally regulated during a transient window, FMRP may be the molecule providing developmental specificity to this pathway.
The Drosophila genome encodes only a single functional mGluR, DmGluRA, allowing a single gene knockout of all mGluR signaling that is unencumbered by potential multi-gene interactions (Bogdanik et al., 2004). Since DmGluRA is the only Drosophila mGluR, it must mediate all conserved functions of the mammalian sub-types. Genetic ablation of DmGluRA clearly demonstrates the importance of mGluR signaling in regulating synaptic structure and function in Drosophila (Bogdanik et al., 2004). Null mutants exhibit reduced synaptic bouton number and a concomitant increase in bouton size at the larval NMJ. In addition, activity-dependent synaptic facilitation is dramatically augmented in animals lacking DmGluRA providing further evidence that this receptor functions at the interface of synaptic structure and function. Based on mammalian studies, it is reasonable to hypothesize that DmGluRA may interact with dFMRP. Indeed, the expression of DmGluRA and dFMRP is inversely correlated in the Drosophila nervous system (Pan et al., 2008), as observed in null mutants of each gene respectively. Moreover, co-removal of dFMRP and DmGluRA is able to restore normal coordinated behavior, which is impaired in DmGluRA single null mutants. Similarly, co-removal of DmGluRA and $\mathrm{dFMRP}$ rescues the increased synaptic arborization and branch number characterizing the $d f m r l$ single null NMJ. This genetic rescue is paralleled using a pharmacological mGluR antagonist (MPEP), which restores the $d f m r 1$ null synaptic architecture towards normal, both at the larval NMJ and the adult brain $\mathrm{MB}$ learning/memory center (Pan et al., 2008). The challenge now is to extend these central brain studies to determine the relationship between mGluR signaling and the role of dFMRP in establishing and modulating synaptic function.

Fortunately, new techniques are emerging that make functional assays in defined Drosophila central brain neurons more accessible. For example, in recent years a primary neuronal culture system has been created by deriving in vitro isolated neurons from pupal brains (Figure 3) (Gu and O'Dowd, 2007; Phillips et al., 2008; $\mathrm{Su}$ and O'Dowd, 2003). These neurons send out processes that form synaptic connections over the course of a couple days, and are capable of both spontaneous and evoked neurotransmitter release, which can be monitored in vitro (Gu et al., 2009). Using the UAS-GAL4 system, primary cultures are derived from animals expressing visual markers (e.g. UAS-GFP) in a defined subset of neurons in order to interrogate functional properties. For example, the lypophilic FM dyes are commonly applied to visually monitor the synaptic vesicle cycle (Figure 3B) (Betz and Bewick, 1992). Depolarizing stimulation causes the dye to be loaded into vesicles and then unloaded upon subsequent depolarization, allowing readouts of both endocytosis and exocytosis. This technique can also be coupled to the process of photoconversion, such that the fluorescent dye signal is converted into an electron dense product visible via high-resolution electron microscopy (Figure 3C). Thus, by photoconverting dye-loaded synapses, quantitative measurements can be made of the capacity of defined synapses to respond to stimulation. Similarly, the genetically encoded synaptopHluorin reporter can be expressed in a neuron type specific manner to also monitor the synaptic vesicle cycle (Poskanzer and Davis, 2004; Poskanzer et al., 2003). SynaptopHluorin is a fusion protein of a pH-sensitive GFP (pHluorin) and the integral synaptic vesicle protein synaptobrevin, such that the phluorin moiety is situated in 

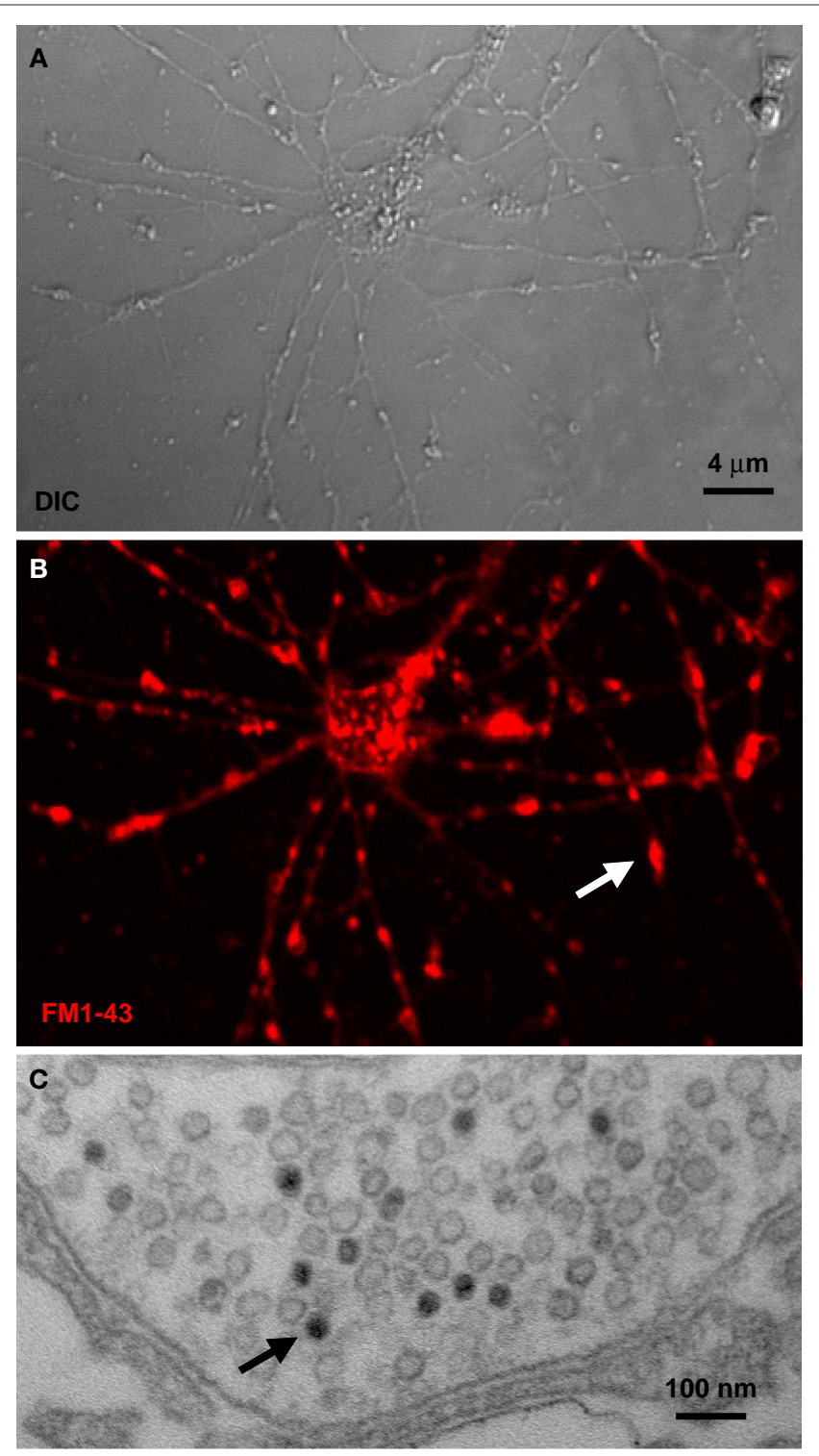

FIGURE 3 | Synaptic vesicle cycle imaging. (A) Nomarski (DIC) image of Drosophila primary brain neuron culture at 8 days in vitro. (B) The lipophilic dye FM1-43 loaded into vesicles by depolarization. Arrow points to a single synaptic bouton. (C) The fluorescent FM1-43 signal can be photoconverted to an electron-dense signal in the presence of diaminobenzene (DAB) with high intensity $490 \mathrm{~nm}$ light. Arrow points to a single labeled synaptic vesicle.

the acidic lumen of the vesicle (Burrone et al., 2006; Miesenbock et al., 1998). Upon stimulation, vesicles fuse with the presynaptic membrane and synaptopHluorin is exposed to the relatively basic extracellular space, causing an increase in fluorescence intensity. Likewise, when the reporter is endocytosed back into a vesicle, the acidic vesicular lumen quenches the synaptopHluorin fluorescence. Monitoring these fluorescence changes in $d f m r 1$ and DmGluRA single and double mutants will extend the functional analysis of this critical pathway.

Of course, it is best to characterize synaptic function in the context of native circuits within the brain. To that end, a Drosophila non-dissociated whole brain explant system has been developed that provides access to relatively undisturbed central circuits for extended periods ( 1 week) (Ayaz et al., 2008; Wang et al., 2003). In principle, the explant brain can be subjected to repeated imaging/ recording from the same neuron or circuit over time. As with primary neuronal cultures, these whole brain explants reportedly maintain synaptic properties and are amenable to both imaging and electrophysiological studies. Thus, it should be possible to monitor activity-dependent processes of development in this form of ex vivo system. As with cultured neurons, synaptic function can be assayed with FM dye labeling using lipophilic dye incorporation into cycling synaptic vesicles and this marker photoconverted to allow ultrastructural analysis at a given time point (Figure 2C). Again the UAS-GAL4 system, or the more powerful MARCM technique described above, can be employed to study single neurons or described circuits. Importantly, both explants and minimally dissected intact brains can be imaged with GFP reporters to visualize circuit neurons, in order to direct cellular electrophysiological recordings (Gu and O'Dowd, 2007; Wilson and Laurent, 2005; Wilson et al., 2004). Exploiting these tools to study temporal regulation of adult circuit development in both $d f m r 1$ null and DmGluRA null animals will be critical components to determine the contribution of these genes to the functional wiring of the brain.

In mammals, one component of mGluR-dependent FMRP function is to regulate the cycling of AMPA glutamate receptors to/from postsynaptic membranes (Moga et al., 2006; Muddashetty et al., 2007; Nakamoto et al., 2007; Waung et al., 2008). There have been many proposed mechanisms by which FMRP may regulate receptor endocytosis and trafficking (Volk et al., 2007). A recent model proposes translational regulation of the FMRP target mRNA encoding Activity Regulated Gene of 3.1 kb (Arg3.1; also called Arc) (Park et al., 2008). Arc expression is increased in synapses in response to synaptic activity and specifically in response to mGluR activation (Chowdhury et al., 2006; Moga et al., 2004; Park et al., 2008; Wang et al., 2009b). In Drosophila, two AMPA-R subtypes, GluRIIA and GluRIIB, are differentially regulated by dFMRP (Figure 4) (Pan and Broadie, 2007). The GluRIIB class of receptors is downregulated in the absence of dFMRP, whereas the GluRIIA class of receptors is upregulated. Conversely, DmGluRA single mutants exhibit a moderate elevation of both receptor classes, and the DmGluRA; dfmrl double null mutant shows an additive effect: higher synaptic abundance of GluRIIA receptors and lower levels of GluRIIB receptors than in the $d f m r 1$ null alone (Pan and Broadie, 2007). These two classes of AMPA-R differ markedly in their functional properties; for example, GluRIIA conducts larger current compared to GluRIIB (Figure 4) (DiAntonio et al., 1999; Sigrist et al., 2002). Thus, this mechanism of glutamate receptor subclass regulation may illustrate a means to directly modulate postsynaptic transmission or, alternatively, to functionally compensate for changes in presynaptic efficacy. Interestingly, FMRP in mammals has been shown to stabilize the mRNA of Postsynaptic Density Protein of 95kDa (PSD-95), which modulates postsynaptic density formation and glutamate receptor localization/function (Zalfa et al., 2007). Similarly in Drosophila, the PSD-95 homolog Discs Large (DLG) strongly regulates synaptic development and modulates the expression of GluRIIB class of receptors, but not the GluRIIA class (Chen and Featherstone, 2005). Thus, an attractive model is forming whereby downstream of DmGluRA synaptic signaling, 


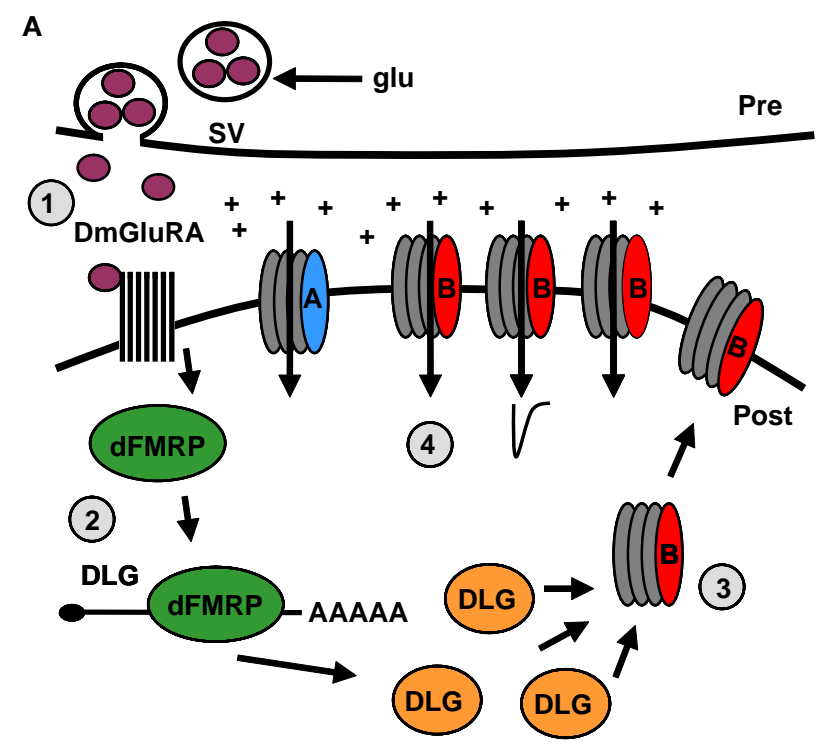

FIGURE 4 | Model of DmGluRA signaling and dFMRP function regulating postsynaptic changes. (A) In step 1, presynaptic glutamate (glu) release from synaptic vesicles (SV) stimulates the DmGluRA receptor to regulate dFMRP. In step 2, dFMRP regulates the stability of DLG/PSD-95 mRNA resulting in an increase in protein levels. In step 3, DLG facilitates the insertion of GluRIIB class

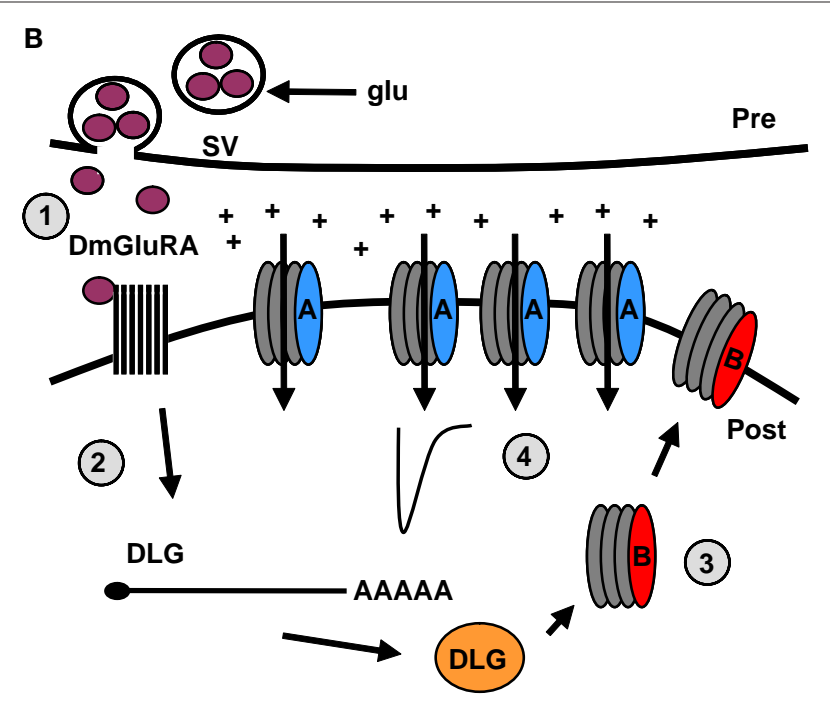

of Drosophila AMPA-like receptors in postsynaptic membrane. In step 4, GluRIIB receptors support reduced excitatory junctional currents. (B) In the absence of dFMRP, DLG mRNA exhibits reduced stability and DLG protein levels are reduced. As a consequence, GluRIIA receptors dominate the synaptic membrane, causing increased excitatory junctional currents.
dFMRP regulates DLG $m R N A$ stability and thereby promotes the specific insertion of GluRIIB receptors into postsynaptic membranes, at the expense of GluRIIA receptors, and thereby modulates synaptic transmission on the basis of GluRIIB functional properties (Figure 4).

This regulation of glutamate receptor subtypes may relate to recently reported changes in the functional synaptic transmission properties of $d f m r 1$ and DmGluRA null mutants (Repicky and Broadie, 2009). Neurotransmission defects in both mutants are most apparent following prolonged periods of moderate to highfrequency stimulation (e.g. $1 \mathrm{~min}, 10 \mathrm{~Hz}$ ). During such a stimulus train, DmGluRA null animals show dramatic augmentation of the synaptic response, which is delayed in double mutant combination with the $d f m r 1$ null. Similarly, the strikingly aberrant premature long term facilitation (LTF) present in DmGluRA null animals is again delayed in the double null mutants (Repicky and Broadie, 2009). Following the high-frequency train, DmGluRA nulls manifest grossly elevated post-tetanic potentiation (PTP), a defect prevented by co-removal of dFMRP. These data suggest that DmGluRA functions in a negative feedback loop in which excess glutamate released during high-frequency transmission binds the DmGluRA receptor to dampen synaptic excitability, and dFMRP functions to suppress the translation of proteins regulating this synaptic excitability. Removal of the translational regulator partially compensates for loss of the receptor and, similarly, loss of the receptor weakly compensates for loss of the translational regulator (Repicky and Broadie, 2009). The precise mechanism of this compensation may involve either pre- or postsynaptic functions, or potentially both.

The above studies clearly indicate a mechanistic requirement for both DmGluRA signaling and dFMRP function in modulating synaptic excitability and neurotransmission strength, but it is still unknown how these properties relate to circuit development. To begin to identify the intersecting pathways with activity, numerous characterized genetic ion channel variants can be expressed in Drosophila neurons in a UAS-GAL4 targeted fashion to alter neuronal firing rates. For example, mutants in the Drosophila Shaker potassium channel have been made to perpetually activate this channel and effectively shunt electrical activity in the neurons expressing it (White et al., 2001). Conversely, a dominant negative (DN) form of Shaker can be expressed to specifically inactivate these channels and thus produce hyperexcitable neurons (Mosca et al., 2005). More specific blocks to neurotransmission may also be used, for example, by expressing the tetanus toxin light chain described above to block synaptic vesicle fusion, or by using DN temperature-sensitive mutants of the shibire gene encoding dynamin, which inactivates the synaptic vesicle cycle by inhibiting endocytosis (Chen et al., 1991; Koenig and Ikeda, 1989; van der Bliek and Meyerowitz, 1991). Combining these techniques in dfmrl and DmGluRA single and double mutants will be a powerful means to dissect the requirements of neuronal and synaptic excitability in order to test functional interactions in neural circuit developmental refinement.

In addition to electrophysiological approaches, recent advances in Drosophila calcium imaging permit monitoring cellular responses to neuronal activation. Several GFP reporters have been generated which alter their fluorescence properties in the presence of calcium, thus allowing the visual monitoring of calcium influx and buffering dynamics (Reiff et al., 2005). Reporters including the camgaroos and gCAMPs are GFP fusion proteins coupled to calmodulin $\mathrm{Ca}^{2+}$ binding domains (Pologruto et al., 2004; Yu et al., 2003). Upon binding with calcium, the GFP reporter undergoes a conformational change to enhance fluorescence intensity (Figure 5). In 


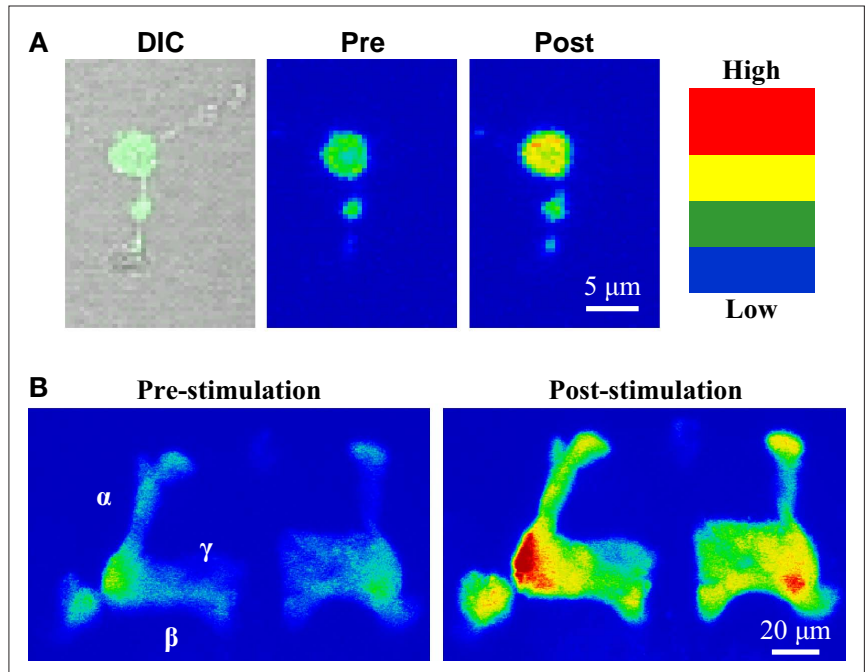

FIGURE 5 | Use of transgenic calcium reporter gCAMP to visualize synaptic activity. (A) OK107-GAL4 driving UAS-gCAMP in primary neuron culture before and after depolarization. (B) OK107-GAL4 driving UAS-gCAMP in whole brain Mushroom Body axonal lobes $(\alpha, \beta, \gamma)$. Depolarization causes fluorescence increases throughout the Mushroom Body.

Drosophila, these reporters can be used either in primary neuronal cultures of identified neuronal subtypes (Figure 5A) or in the intact brain (Figure 5B). In addition, the commonly utilized cameleon reporters are a fusion of the calmodulin binding domain situated between CFP and YFP (Miyawaki et al., 1997). The cameleon reporter relies on a FRET based mechanism to generate fluorescence changes in response to calcium binding. With this reporter, $\mathrm{Ca}^{2+}$ binding is monitored by a concomitant decrease in CFP emission and an increase in YFP emission (Fiala and Spall, 2003). Similarly, reporters based on the calcium-binding troponin $\mathrm{C}$ protein have been optimized by mutageneisis (TN-XXL) to produce high affinity calcium binding and reliable responses to stimulation (Mank et al., 2008). TN-XXL is sensitive over a range of stimulations and functions in both flies and mice as a stable monitor of calcium dynamics. Each transgenic reporter has distinct advantages and disadvantages, most notably in the respective signal to noise ratios, but they are continually being modified to provide the best physiological responses to neuronal activation.

\section{BEHAVIORAL OUTPUTS OF ACTIVITY REGULATED CIRCUITS}

The activity-dependent refinement of neural circuits results in a final wiring optimized for behavioral outputs. Of course, circuits remain plastic in mature animals, permitting constant modulation to adapt to changing conditions, to learn from environmental stimuli and to remember lessons learned. It may be that activity-dependent refinement during development is required to lay a foundation for maintained synaptic plasticity. Drosophila is well suited for the analysis of circuits driving quantifiable output behaviors. For example, MB-dependent olfactory associative learning and progressive memory consolidation has been a particularly important focus in this system (Akalal et al., 2006; Connolly et al., 1996; de Belle and Heisenberg, 1994; Dubnau et al., 2001; Heisenberg et al., 1985; Tully and Quinn, 1985). Drosophila possess at least four distinct phases of memory (Isabel et al., 2004); short term memory (STM) and middle term memory, which persist each on the order of minutes, and anesthesia-resistant memory (ARM) and long term memory (LTM), which persist on the order of days to, theoretically, the end of the animal's lifespan. Critically, only the latter two memory phases are dependent on de novo translation, with LTM alone being absolutely dependent on protein synthesis, both for its formation and maintenance (Isabel et al., 2004; Tully et al., 1994; Yu et al., 2006). Experimentally, memory has been best characterized using an olfactory associative model whereby an animal is exposed to an odor/electrical shock pairing, learning to avoid this association in favor of an odor which has not been coupled to an electric shock (Tully and Quinn, 1985). While short and middle term memories are generated by multiple training sessions performed back to back with no breaks in between, this "mass training" protocol does not induce LTM (Yin et al., 1994). LTM is only induced by spacing training sessions (e.g. $\sim 15 \mathrm{~min}$ apart) and is blocked in the presence of protein synthesis inhibitors. Thus, there is an obvious potential link between protein synthesis-dependent LTM and the translational repressor FMRP whose loss is hallmarked by cognitive and memory impairments in FXS patients. FMRP may be required in an activity-dependent manner to establish the circuit map necessary for both learning and memory formation.

In Drosophila, null $d f m r 1$ mutants have a relatively mild defect in learning formation and more profound defect in memory consolidation in the above associative olfactory paradigm (Bolduc et al., 2008). Importantly, the strong LTM defect only manifested after spaced training. dFMRP expression was broadly upregulated in the brain specifically in response to spaced training, but was unaffected by mass training protocols (Bolduc et al., 2008). Surprisingly, this upregulation appeared widespread and not restricted to any specific brain region or defined circuitry (e.g. Mushroom Body). Acute over-expression of dFMRP prior to training also blocked LTM, suggesting that dFMRP acts in acute memory consolidation; elevating dFMRP after training had no effect. Blocking protein synthesis in $d f m r 1$ null animals rescued these memory deficits, suggesting that enhanced protein synthesis is sufficient to explain the failure to consolidate memories (Bolduc et al., 2008). In parallel with the dFMRP requirement, mutants of the staufen gene, encoding a protein involved in mRNA translocation, share a similar defect in LTM consolidation. The two proteins appear to interact in protein synthesis-dependent memory formation. Heterozygous mutation of each gene alone causes no memory defects, but double heterozygotes (staufen/+; dfmr1/+) show dramatic loss of LTM consolidation after spaced training, with no effect on mass training memory (Bolduc et al., 2008). As predicted by the Gq hypothesis, DmGluRA antagonists significantly rescued memory consolidation defects.

dFMRP is also involved in Drosophila courtship, a learning and memory behavior that requires the integration of multiple sensory modalities (Joiner and Griffith, 2000; McBride et al., 2005). Null $d f m r 1$ males fail to effectively court females and have defective memory associated with this social interaction. These defects were rescued by feeding animals mGluR antagonists, which provides further support for this synaptic signaling mechanism in regulating dFMRP function (McBride et al., 2005). Interestingly, mGluR antagonists provide the most effective rescue of $d f m r 1$ defects when supplied throughout development, as opposed to acutely in adult animals, which caused an adverse affect on memory formation 
in wildtype animals. Mechanistically, it is of note that in oocytes dFMRP binds to and negatively regulates the Drosophila Orb protein, a homolog of mammalian cytoplasmic polyadenylation element-binding protein (CPEB) (Costa et al., 2005). In the brain, the CPEB RNA-binding protein is proposed to "mark" synapses locally in response to signaling via mGluRs and the Drosophila neural specific Orb2 is essential for Drosophila courtship conditioning induced LTM (Keleman et al., 2007; Si et al., 2003). Thus, it will be critical to ascertain whether dFMRP interacts with Orb2 to regulate general, or paradigm specific LTM. Unfortunately, the identity of the neural circuits involved in this complex social behavioral repertoire are unknown, precluding close developmental analysis of circuit structure and function at this time.

In contrast, the circuitry of another dFMRP-dependent complex behavior, circadian rhythm cycling, is particularly well characterized, including the large and small lateral clock neurons in the central brain (Helfrich-Forster, 2003). Large lateral neurons exhibit overextension and apparent defasiculation in $d f m r 1$ null animals, phenotypes that are proportional to the dosage of gene removal (Morales et al., 2002). The mechanism of these structural changes is dependent on the dFMRP mRNA target, actin-binding chickadee/profilin (Reeve et al., 2005). Reducing chickadee/profilin protein levels in $d f m r 1$ null animals can rescue over-elaboration phenotypes. Consistent with clock circuit dysfunction, null $d f m r 1$ animals exhibit profoundly disrupted circadian activity cycles and prolonged bouts of sleep (Bushey et al., 2009; Dockendorff et al., 2002; Inoue et al., 2002; Morales et al., 2002). So far, these defects have not been attributed to either aberrant mGluR activation or direct defects in clock control though the abundance of the clock protein period (Per) is elevated throughout the circadian cycle in $d f m r 1$ null animals. Thus, it will be necessary to further investigate the developmental defects within this circuitry to understand the role of dFMRP in these behavioral manifestations. Lastly, there are numerous other well-characterized Drosophila behaviors, such as visual discrimination, aggression and pain avoidance which all require the integration of multiple sensory and higher order neural circuits (Chen et al., 2002; Duistermars and Frye, 2008; Guo and Gotz, 1997; Manev and

\section{REFERENCES}

Akalal, D. B., Wilson, C. F., Zong, L., Tanaka, N. K., Ito, K., and Davis, R. L. (2006). Roles for Drosophila mushroom body neurons in olfactory learning and memory. Learn. Mem. 13, 659-668.

Ayaz, D., Leyssen, M., Koch, M., Yan, J., Srahna, M., Sheeba, V., Fogle, K. J., Holmes, T. C., and Hassan, B. A. (2008). Axonal injury and regeneration in the adult brain of Drosophila. J. Neurosci. 28, 6010-6021.

Barth, M., Hirsch, H. V., Meinertzhagen, I. A., and Heisenberg, M. (1997). Experiencedependent developmental plasticity in the optic lobe of Drosophila melanogaster. J. Neurosci. 17, 1493-1504.

Bassell, G. J., and Warren, S. T. (2008) Fragile X syndrome: loss of local mRNA regulation alters synaptic

Dimitrijevic, 2004; Schuster et al., 2002; Tracey et al., 2003; Xu et al. 2006; Yurkovic et al., 2006). Using the tools discussed in this review, and elsewhere in this issue, it will soon be possible to dissect these circuits to understand the role of activity and dFMRP in laying the foundation for these diverse behavioral repertoires.

\section{CONCLUDING THOUGHTS}

It still remains unclear the extent to which dFMRP functions in mediating activity-dependent developmental refinement versus maintained plasticity to drive the proper manifestation of complex behavioral outputs. Currently, the most disease-relevant behavioral data in Drosophila is the defective MB circuit associative learning and memory consolidation, and this will certainly remain an important brain region for understanding the circuit requirements of dFMRP. But what about other circuits? Does dFMRP regulate neuronal activity the same way in all circuits? Is metabotropic receptor signaling upstream of dFMRP function in every circuit? Does dFMRP play a similar late-stage role in activity-dependent refinement in all circuits? If there are differences, then can those differences be attributed to specific molecular functions of dFMRP? Special attention will need to be paid to the developmental control mediated by dFMRP, and particularly the synaptic pruning function. The key molecular components of this mechanism still need to be determined. Is pruning broadly used to establish maps in all circuits, or is it a specialized program for select brain regions or neuronal subtypes? As advances in Drosophila transgenic tools accelerate our ability to investigate these processes, these vital tools will continue to aid in our understanding of the molecular mechanisms of disorders such as FXS, hastening our ability to engineer effective intervention strategies.

\section{ACKNOWLEDGEMENTS}

We are grateful to members of the Broadie Lab for comments and discussion on this manuscript, especially Dr. Cheryl Gatto and Dr. Sarah Yang. We also thank Dr. Cheryl Gatto, Dr. Luyuan Pan, Niranjana Vijayakrishnan, and Elvin Woodruff III for contributions to figures. This work was supported by NIH grant MH084989 to K.B.

regulates activity-dependent synaptic facilitation and fine synaptic morphology. J. Neurosci. 24, 9105-9116.

Bolduc,F.V., Bell, K., Cox,H., Broadie, K. S and Tully, T. (2008). Excess protein synthesis in Drosophila fragile $\mathrm{X}$ mutants impairs long-term memory. Nat. Neurosci. 11, 1143-1145.

Borue, X., Cooper, S., Hirsh,J., Condron, B. and Venton, B. J. (2009). Quantitative evaluation of serotonin release and clearance in Drosophila. J. Neurosci. Methods 179, 300-308.

Boyden, E. S., Zhang, F., Bamberg, E., Nagel, G., and Deisseroth, K. (2005). Millisecond-timescale, genetically targeted optical control of neural activity. Nat. Neurosci. 8, 1263-1268.

Broadie, K., and Bate, M. (1993). Activitydependent development of the neuromuscular synapse during Drosophila embryogenesis. Neuron 11, 607-619.
Broadie, K., Prokop, A., Bellen, H. J., O'Kane, C. J., Schulze, K. L., and Sweeney, S. T. (1995). Syntaxin and synaptobrevin function downstream of vesicle docking in Drosophila. Neuron 15, 663-673.

Budnik, V., Zhong, Y., and Wu, C. F. (1990). Morphological plasticity of motor axons in Drosophila mutants with altered excitability. J. Neurosci. 10, 3754-3768.

Burrone, J., Li, Z., and Murthy, V. N. (2006). Studying vesicle cycling in presynaptic terminals using the genetically encoded probe synaptopHluorin. Nat. Protoc. 1, 2970-2978.

Bushey, D., Tononi, G., and Cirelli, C. (2009). The Drosophila fragile X mental retardation gene regulates sleep need. J. Neurosci. 29, 1948-1961. Broadie, $\mathrm{K}$, and $\mathrm{Parr}$ (2004). The Drosophila metabotropic glutamate receptor DmGluRA
Cang, J., Kaneko, M., Yamada, J., Woods, G., Stryker, M. P., and Feldheim, D. A. 
(2005a).Ephrin-as guide the formation of functional maps in the visual cortex. Neuron 48, 577-589.

Cang, J., Renteria, R. C., Kaneko, M., Liu, X., Copenhagen, D. R., and Stryker, M.P.(2005b). Development of precise maps in visual cortex requires patterned spontaneous activity in the retina. Neuron 48, 797-809.

Chandrasekaran, A. R., Plas, D. T., Gonzalez, E., and Crair, M. C. (2005). Evidence for an instructive role of retinal activity in retinotopic map refinement in the superior colliculus of the mouse. J. Neurosci. 25, 6929-6938.

Chen, H. X., and Roper, S. N. (2004). Tonic activity of metabotropic glutamate receptors is involved in developmental modification of short-term plasticity in the neocortex. J. Neurophysiol. 92, 838-844.

Chen, K., and Featherstone, D. E. (2005). Discs-large (DLG) is clustered by presynaptic innervation and regulates postsynaptic glutamate receptor subunit composition in Drosophila. BMC Biol. 3, 1 .

Chen, M. S., Obar, R. A., Schroeder, C. C., Austin, T. W., Poodry, C. A., Wadsworth, S. C., and Vallee, R. B. (1991). Multiple forms of dynamin are encoded by shibire, a Drosophila gene involved in endocytosis. Nature 351, 583-586.

Chen, S., Lee, A. Y., Bowens, N. M., Huber, R., and Kravitz, E. A. (2002). Fighting fruit flies: a model system for the study of aggression. Proc. Natl. Acad. Sci. U.S.A. 99, 5664-5668.

Chiba,A.,Shepherd,D., andMurphey, R. K. (1988). Synaptic rearrangement during postembryonic development in the cricket. Science 240, 901-905.

Chowdhury, S., Shepherd, J. D., Okuno, H., Lyford, G., Petralia, R. S., Plath, N., Kuhl, D., Huganir, R. L., and Worley, P. F. (2006). Arc/Arg3.1 interacts with the endocytic machinery to regulate AMPA receptor trafficking. Neuron 52, 445-459.

Cohen, D., Pichard, N., Tordjman, S., Baumann, C., Burglen, L., Excoffier, E., Lazar, G., Mazet, P., Pinquier, C., Verloes, A., and Heron, D. (2005). Specific genetic disorders and autism: clinical contribution towards their identification. J. Autism Dev. Disord. 35, 103-116

Comery, T. A., Harris, J. B., Willems, P. J., Oostra, B. A., Irwin, S. A., Weiler, I. J., and Greenough, W. T. (1997). Abnormal dendritic spines in fragile $\mathrm{X}$ knockout mice: maturation and pruning deficits. Proc. Natl. Acad. Sci. U.S.A. 94, 5401-5404.

Conn, P. J., and Pin, J. P. (1997). Pharmacology and functions of metabotropic glutamate receptors.
Annu. Rev. Pharmacol. Toxicol. 37, 205-237.

Connolly, J. B., Roberts, I. J., Armstrong, J. D., Kaiser, K., Forte, M., Tully, T., and O'Kane, C. J. (1996). Associative learning disrupted by impaired Gs signaling in Drosophila mushroom bodies. Science 274, 2104-2107.

Costa, A., Wang, Y., Dockendorff, T. C., Erdjument-Bromage, H., Tempst, P., Schedl, P., and Jongens, T. A. (2005) The Drosophila fragile X protein functions as a negative regulator in the orb autoregulatory pathway. Dev. Cell 8, 331-342.

Cutforth, T., Moring, L., Mendelsohn, M., Nemes, A., Shah, N. M., Kim, M. M., Frisen, J., and Axel, R. (2003). Axonal ephrin-As and odorant receptors: coordinate determination of the olfactory sensory map. Cell 114, 311-322.

Davidkova, G., and Carroll, R. C. (2007). Characterization of the role of microtubule-associated protein $1 \mathrm{~B}$ in metabotropic glutamate receptormediated endocytosis of AMPA receptors in hippocampus. J. Neurosci. 27, 13273-13278.

de Belle, J. S., and Heisenberg, M. (1994). Associative odor learning in Drosophila abolished by chemical ablation of mushroom bodies. Science 263, 692-695.

de Vrij, F. M., Levenga, J., van der Linde, H. C., Koekkoek, S. K., De Zeeuw, C.I., Nelson, D.L., Oostra, B. A., and Willemsen, R. (2008). Rescue of behavioral phenotype and neuronal protrusion morphology in Fmr1 KO mice. Neurobiol. Dis. 31, 127-132.

Devaud, J. M., Acebes, A., and Ferrus, A. (2001). Odor exposure causes central adaptation and morphological changes in selected olfactory glomeruli in Drosophila. J. Neurosci. 21, 6274-6282.

Devaud, J.M.,Acebes, A., Ramaswami, M., and Ferrus, A. (2003). Structural and functional changes in the olfactory pathway of adult Drosophila take place at a critical age. J. Neurobiol. 56, 13-23.

DiAntonio, A., Petersen, S. A., Heckmann, M., and Goodman, C. S. (1999). Glutamate receptor expression regulates quantal size and quantal content at the Drosophila neuromuscular junction. J. Neurosci. 19, 3023-3032.

Dockendorff,T.C.,Su,H.S.,McBride, S. M., Yang, Z., Choi, C. H., Siwicki, K. K., Sehgal, A., and Jongens, T. A. (2002). Drosophila lacking dfmrl activity show defects in circadian output and fail to maintain courtship interest. Neuron 34, 973-984.

Doherty, J. J., Alagarsamy, S., Bough, K. J., Conn, P. J., Dingledine, R., and
Mott, D. D. (2004). Metabotropic glutamate receptors modulate feedback inhibition in a developmentally regulated manner in rat dentate gyrus. J. Physiol. 561, 395-401.

Dolen, G., Osterweil, E., Rao, B. S. Smith, G. B., Auerbach, B. D., Chattarji, S., and Bear, M. F. (2007). Correction of fragile $\mathrm{X}$ syndrome in mice. Neuron 56, 955-962.

Dubnau, J., Grady, L., Kitamoto, T., and Tully, T. (2001). Disruption of neurotransmission in Drosophila mushroom body blocks retrieval but not acquisition of memory. Nature 411, 476-480.

Duistermars, B. J., and Frye, M. A. (2008). Crossmodal visual input for odor tracking during fly flight. Curr. Biol. 18, 270-275.

Fahrbach, S. E., Giray, T., and Robinson, G. E. (1995). Volume changes in the mushroom bodies of adult honey bee queens. Neurobiol. Learn. Mem. 63, 181-191.

Feinstein, P., Bozza, T., Rodriguez, I., Vassalli, A., and Mombaerts, P. (2004). Axon guidance of mouse olfactory sensory neurons by odorant receptors and the beta 2 adrenergic receptor. Cell 117, 833-846.

Feinstein, P., and Mombaerts, P. (2004). A contextual model for axonal sorting into glomeruli in the mouse olfactory system. Cell 117, 817-831.

Ferrari, F., Mercaldo, V., Piccoli, G. Sala, C., Cannata, S., Achsel, T., and Bagni, C. (2007). The fragile X mental retardation protein-RNP granules show an mGluR-dependent localization in the post-synaptic spines. $\mathrm{Mol}$. Cell. Neurosci. 34, 343-354.

Fiala, A., and Spall, T. (2003). In vivo calcium imaging of brain activity in Drosophila by transgenic cameleon expression. Sci. STKE 2003, PL6.

Fischer, J.A., Giniger, E., Maniatis, T., and Ptashne, M. (1988). GAL4 activates transcription in Drosophila. Nature 332, 853-856.

Galvez, R., Gopal, A. R., and Greenough, W. T. (2003). Somatosensory cortical barrel dendritic abnormalities in a mouse model of the fragile X mental retardation syndrome. Brain Res. 971, 83-89.

Galvez, R., and Greenough, W. T. (2005). Sequence of abnormal dendritic spine development in primary somatosensory cortex of a mouse model of the fragile X mental retardation syndrome. Am. J. Med. Genet. 135, 155-160.

Galvez, R., Smith, R. L., and Greenough, W. T. (2005). Olfactory bulb mitral cell dendritic pruning abnormalities in a mouse model of the Fragile-X mental retardation syndrome: further support for FMRP's involvement in dendritic development Brain Res. 157, 214-216.

Gatto, C. L., and Broadie, K. (2008). Temporal requirements of the fragile $\mathrm{X}$ mental retardation protein in the regulation of synaptic structure. Development 135, 2637-2648.

Gu, H., Jiang, S. A., Campusano, J. M., Iniguez, J., Su, H., Hoang, A. A., Lavian, M., Sun, X., and O'Dowd, D. K. (2009). Cav2-type calcium channels encoded by cac regulate APindependent neurotransmitter release at cholinergic synapses in adult Drosophila brain. J. Neurophysiol. 101, 42-53.

Gu, H., and O’Dowd, D. K. (2007). Whole cell recordings from brain of adult Drosophila. J. Vis. Exp. 248.

Guo, A., and Gotz, K. G. (1997). Association of visual objects and olfactory cues in Drosophila. Learn. Mem. 4, 192-204.

Hagerman, R. J., Ono, M. Y., and Hagerman, P. J. (2005). Recent advances in fragile $\mathrm{X}$ : a model for autism and neurodegeneration. Curr. Opin. Psychiatry 18, 490-496.

Hannan, A. J., Blakemore, C., Katsnelson, A., Vitalis, T., Huber, K. M., Bear, M., Roder, J., Kim, D., Shin, H. S., and Kind, P.C.(2001).PLC-betal, activated via mGluRs, mediates activitydependent differentiation in cerebral cortex. Nat. Neurosci. 4, 282-288.

Hardie, R. C., Peretz, A., Pollock, J. A., and Minke, B. (1993). $\mathrm{Ca}^{2+}$ limits the development of the light response in Drosophila photoreceptors. Proc. Biol. Sci. 252, 223-229.

Heisenberg, M., Borst, A., Wagner, S., and Byers, D. (1985). Drosophila mushroom body mutants are deficient in olfactory learning. J. Neurogenet. 2, $1-30$.

Helfrich-Forster, C. (2003). The neuroarchitecture of the circadian clock in the brain of Drosophila melanogaster. Microsc. Res. Tech. 62, 94-102.

Hiesinger, P. R., Zhai, R. G., Zhou, Y., Koh, T.W., Mehta, S. Q., Schulze, K. L. Cao, Y., Verstreken, P., Clandinin, T. R., Fischbach, K. F., Meinertzhagen, I. A., and Bellen, H. J. (2006). Activityindependent prespecification of synaptic partners in the visual map of Drosophila. Curr. Biol. 16, 1835-1843.

Hornstein, N. J., Pulver, S. R., and Griffith, L.C. (2009). Channelrhodopsin 2 mediated stimulation of synaptic potentials at Drosophila neuromuscular junctions. J. Vis. Exp.

Hou, L., Antion, M. D., Hu, D., Spencer, C. M., Paylor, R., and Klann, E. (2006). Dynamic translational and proteasomal regulation of 
fragile $\mathrm{X}$ mental retardation protein controls mGluR-dependent long-term depression. Neuron 51, 441-454.

Imai, T., Suzuki, M., and Sakano, H. (2006). Odorant receptor-derived cAMP signals direct axonal targeting. Science 314, 657-661.

Incorpora, G., Sorge, G., Sorge, A., and Pavone, L. (2002). Epilepsy in fragile X syndrome. Brain Dev. 24, 766-769.

Inoue, S., Shimoda, M., Nishinokubi, I., Siomi, M. C., Okamura, M., Nakamura, A., Kobayashi, S., Ishida, N., and Siomi, H. (2002). A role for the Drosophila fragile X-related gene in circadian output. Curr. Biol. 12, 1331-1335.

Irwin, S. A., Christmon, C. A., Grossman, A. W., Galvez, R., Kim, S. H., DeGrush, B. J., Weiler, I. J., and Greenough, W. T. (2005). Fragile $\mathrm{X}$ mental retardation protein levels increase following complex environment exposure in rat brain regions undergoing active synaptogenesis. Neurobiol. Learn. Mem. 83, 180-187.

Irwin, S.A., Idupulapati, M., Gilbert, M. E., Harris, J. B., Chakravarti, A. B., Rogers, E. J., Crisostomo, R. A., Larsen, B.P.,Mehta,A.,Alcantara, C. J., Patel, B., Swain, R. A., Weiler, I. J., Oostra, B. A., and Greenough, W. T. (2002). Dendritic spine and dendritic field characteristics of layer $V$ pyramidal neurons in the visual cortex of fragile-X knockout mice. Am. J. Med. Genet. 111, 140-146.

Irwin, S. A., Patel, B., Idupulapati, M., Harris, J. B., Crisostomo, R. A., Larsen, B. P., Kooy, F., Willems, P. J., Cras, P., Kozlowski, P. B., Swain, R. A., Weiler, I. J., and Greenough, W. T. (2001). Abnormal dendritic spine characteristics in the temporal and visual cortices of patients with fragile-X syndrome: a quantitative examination. Am. J. Med. Genet. 98, 161-167.

Isabel, G., Pascual, A., and Preat, T. (2004). Exclusive consolidated memory phases in Drosophila. Science 304, 1024-1027.

Jarecki, J., and Keshishian, H. (1995). Role of neural activity during synaptogenesis in Drosophila. J. Neurosci. 15, 8177-8190.

Jefferis, G. S., Vyas, R. M., Berdnik, D., Ramaekers, A., Stocker, R. F., Tanaka, N. K., Ito, K., and Luo, L. (2004). Developmental origin of wiring specificity in the olfactory system of Drosophila. Development 131, 117-130.

Joiner, M. A., and Griffith, L. C. (2000). Visual input regulates circuit configuration in courtship conditioning of Drosophila melanogaster. Learn. Mem. 7, 32-42.
Keleman, K., Kruttner, S., Alenius, M., and Dickson, B. J. (2007). Function of the Drosophila CPEB protein Orb2 in long-term courtship memory. Nat. Neurosci. 10, 1587-1593.

Khandjian,E.W.,Fortin,A., Thibodeau, A., Tremblay, S., Cote, F., Devys, D., Mandel, J.L., and Rousseau, F. (1995). A heterogeneous set of FMR1 proteins is widely distributed in mouse tissues and is modulated in cell culture. Hum. Mol. Genet. 4, 783-789.

Koenig, J. H., and Ikeda, K. (1989). Disappearance and reformation of synaptic vesicle membrane upon transmitter release observed under reversible blockage of membrane retrieval. J. Neurosci. 9, 3844-3860.

Lee, T., and Luo, L. (2001). Mosaic analysis with a repressible cell marker (MARCM) for Drosophila neural development. Trends Neurosci. 24, 251-254.

Lin, D. M., Wang, F., Lowe, G., Gold, G. H., Axel, R., Ngai, J., and Brunet, L. (2000). Formation of precise connections in the olfactory bulb occurs in the absence of odorant-evoked neuronal activity. Neuron 26, 69-80.

Liu, Y., Fields, R. D., Festoff, B. W., and Nelson, P.G. (1994). Proteolytic action of thrombin is required for electrical activity-dependent synapse reduction. Proc. Natl. Acad. Sci. U.S.A. 91, 10300-10304.

Manev, H., and Dimitrijevic, N. (2004). Drosophila model for in vivo pharmacological analgesia research. Eur. J. Pharmacol. 491, 207-208.

Mank, M., Santos, A. F., Direnberger, S., Mrsic-Flogel, T. D., Hofer, S. B., Stein, V., Hendel, T., Reiff, D. F., Levelt, C., Borst, A., Bonhoeffer, T., Hubener, M., and Griesbeck, O. (2008). A genetically encoded calcium indicator for chronic in vivo two-photon imaging. Nat. Methods 5, 805-811.

Mares, P. (2009). Age-dependent anticonvulsant action of antagonists of group I glutamate metabotropic receptors in rats. Epilepsy Res. 83, 215-223.

Marks, C.A.,Cheng, K., Cummings, D. M., and Belluscio, L. (2006). Activitydependent plasticity in the olfactory intrabulbar map. J. Neurosci. 26, $11257-11266$

Mateo,Z., and Porter,J.T. (2007). Group II metabotropic glutamate receptors inhibit glutamate release at thalamocortical synapses in the developing somatosensory cortex. Neuroscience 146, 1062-1072.

McBride, S. M., Choi, C. H., Wang, Y., Liebelt, D., Braunstein, E., Ferreiro, D., Sehgal, A., Siwicki, K. K., Dockendorff, T. C., Nguyen, H. T.,
McDonald, T. V., and Jongens, T. A. (2005). Pharmacological rescue of synaptic plasticity, courtship behavior, and mushroom body defects in a Drosophila model of fragile X syndrome. Neuron 45, 753-764.

McKinney, B. C., Grossman, A. W., Elisseou, N.M., and Greenough, W. T. (2005). Dendritic spine abnormalities in the occipital cortex of C57BL/6 Fmrl knockout mice. Am. J. Med. Genet. B Neuropsychiatr. Genet. 136, 98-102.

Miesenbock, G., De Angelis, D. A., and Rothman, J. E. (1998). Visualizing secretion and synaptic transmission with $\mathrm{pH}$-sensitive green fluorescent proteins. Nature 394, 192-195.

Miyawaki, A., Llopis, J., Heim, R., McCaffery, J. M., Adams, J. A., Ikura, M., and Tsien, R. Y. (1997). Fluorescent indicators for $\mathrm{Ca}^{2+}$ based on green fluorescent proteins and calmodulin. Nature 388, 882-887.

Moga,D.E.,Calhoun,M.E.,Chowdhury, A., Worley, P., Morrison, J. H., and Shapiro, M. L. (2004). Activityregulated cytoskeletal-associated protein is localized to recently activated excitatory synapses. Neuroscience 125 7-11.

Moga, D. E., Shapiro, M. L., and Morrison, J. H. (2006). Bidirectional redistribution of AMPA but not NMDA receptors after perforant path simulation in the adult rat hippocampus in vivo. Hippocampus 16 990-1003.

Morales, J., Hiesinger, P. R., Schroeder, A. J., Kume, K., Verstreken, P., Jackson, F. R., Nelson, D. L., and Hassan, B. A. (2002). Drosophila fragile X protein, DFXR, regulates neuronal morphology and function in the brain. Neuron 34, 961-972.

Mosca, T. J., Carrillo, R. A., White, B. H., and Keshishian, H. (2005). Dissection of synaptic excitability phenotypes by using a dominant-negative Shaker K+ channel subunit. Proc. Natl. Acad. Sci. U.S.A. 102, 3477-3482.

Muddashetty, R. S., Kelic, S., Gross, C., Xu, M., and Bassell, G. J. (2007). Dysregulated metabotropic glutamate receptor-dependent translation of AMPA receptor and postsynaptic density-95 mRNAs at synapses in a mouse model of fragile $\mathrm{X}$ syndrome. J. Neurosci. 27, 5338-5348.

Musumeci, S. A., Hagerman, R. J., Ferri, R., Bosco, P., Dalla Bernardina, B., Tassinari, C. A., De Sarro, G. B., and Elia, M. (1999). Epilepsy and EEG findings in males with fragile $\mathrm{X}$ syndrome. Epilepsia 40, 1092-1099.

Nagel, G., Szellas, T., Huhn, W., Kateriya, S., Adeishvili, N., Berthold, P., Ollig, D. Hegemann, P., and Bamberg, E.
(2003). Channelrhodopsin-2, a directly light-gated cation-selective membrane channel. Proc. Natl. Acad. Sci. U.S.A. 100, 13940-13945.

Nakamoto, M., Nalavadi, V., Epstein, M. P., Narayanan, U., Bassell, G. J., and Warren, S. T. (2007). Fragile X mental retardation protein deficiency leads to excessive mGluR5-dependent internalization of AMPA receptors. Proc. Natl. Acad. Sci. U.S.A. 104, 15537-15542.

Nikolic, K., Grossman, N., Grubb, M. S., Burrone, J., Toumazou, C., and Degenaar, P. (2009). Photocycles of channelrhodopsin-2. Photochem. Photobiol. 85, 400-411.

Nimchinsky, E. A., Oberlander, A. M., and Svoboda, K. (2001). Abnormal development of dendritic spines in FMR1 knock-out mice. J. Neurosci. 21, 5139-5146.

Nosyreva, E. D., and Huber, K. M. (2006). Metabotropic receptordependent long-term depression persists in the absence of protein synthesis in the mouse model of fragile X syndrome. J. Neurophysiol. 95, 3291-3295.

Oland, L. A., Pott, W. M., Bukhman, G., Sun, X. J., and Tolbert, L. P. (1996). Activity blockade does not prevent the construction of olfactory glomeruli in the moth Manduca sexta. Int. J. Dev. Neurosci. 14, 983-996.

Osterwalder, T., Yoon, K. S., White, B. H., and Keshishian, H. (2001). A conditional tissue-specific transgene expression system using inducible GAL4. Proc. Natl. Acad. Sci. U.S.A. 98, 12596-12601.

Ostroff, L. E., Fiala, J. C., Allwardt, B., and Harris, K. M. (2002). Polyribosomes redistribute from dendritic shafts into spines with enlarged synapses during LTP in developing rat hippocampal slices. Neuron 35, 535-545.

Pan, L., and Broadie, K. S. (2007). Drosophila fragile $\mathrm{X}$ mental retardation protein and metabotropic glutamate receptor A convergently regulate the synaptic ratio of ionotropic glutamate receptor subclasses. J. Neurosci. 27, 12378-12389.

Pan, L., Woodruff, E., 3rd, Liang, P., and Broadie, K. (2008). Mechanistic relationships between Drosophila fragileX mental retardation protein and metabotropic glutamate receptor A signaling. Mol. Cell. Neurosci. 37, 747-760.

Pan, L., Zhang, Y. Q., Woodruff, E., and Broadie, K. (2004). The Drosophila fragile $\mathrm{X}$ gene negatively regulates neuronal elaboration and synaptic differentiation. Curr. Biol. 14, 1863-1870

Park, S., Park, J. M., Kim, S., Kim, J. A. Shepherd, J. D., Smith-Hicks, C. L., 
Chowdhury, S., Kaufmann, W., Kuhl, D., Ryazanov, A. G., Huganir, R. L., Linden, D. J., and Worley, P. F. (2008). Elongation factor 2 and fragile $\mathrm{X}$ mental retardation protein control the dynamic translation of Arc/Arg3.1 essential for mGluR-LTD. Neuron 59, 70-83.

Phillips, S. E., Woodruff, E. A., 3rd, Liang, P., Patten, M., and Broadie, K. (2008). Neuronal loss of Drosophila NPCla causes cholesterol aggregation and age-progressive neurodegeneration. J. Neurosci. 28, 6569-6582.

Pieretti, M., Zhang, F. P., Fu, Y. H., Warren, S. T., Oostra, B. A., Caskey, C. T., and Nelson, D. L. (1991). Absence of expression of the FMR-1 gene in fragile X syndrome. Cell 66, 817-822.

Pin, J. P., and Duvoisin, R. (1995). The metabotropic glutamate receptors: structure and functions. Neuropharmacology 34, 1-26.

Pologruto, T. A., Yasuda, R., and Svoboda, K. (2004). Monitoring neural activity and $\left[\mathrm{Ca}^{2+}\right]$ with genetically encoded $\mathrm{Ca}^{2+}$ indicators. J. Neurosci. 24, 9572-9579.

Poskanzer, K. E., and Davis, G. W. (2004). Mobilization and fusion of a nonrecycling pool of synaptic vesicles under conditions of endocytic blockade. Neuropharmacology 47, 714-723.

Poskanzer, K. E., Marek, K. W., Sweeney, S. T., and Davis, G. W. (2003). Synaptotagmin I is necessary for compensatory synaptic vesicle endocytosis in vivo. Nature 426, 559-563.

Pulver, S. R., Pashkovski, S. L., Hornstein, N. J., Garrity, P. A., and Griffith, L. C. (2009). Temporal dynamics of neuronal activation by channelrhodopsin-2 and TRPA1 determine behavioral output in Drosophila larvae. J. Neurophysiol. 101, 3075-3088.

Radu, I., Bamann, C., Nack, M., Nagel, G., Bamberg, E., and Heberle, J. (2009). Conformational changes of channelrhodopsin-2. J. Am. Chem. Soc. 131, 7313-7319.

Reeve, S. P., Bassetto, L., Genova, G. K., Kleyner, Y., Leyssen, M., Jackson, F. R., and Hassan, B. A. (2005). The Drosophila fragile X mental retardation protein controls actin dynamics by directly regulating profilin in the brain. Curr. Biol. 15, 1156-1163.

Reid, S. N., and Romano, C. (2001). Developmental and sensorydependent changes of group II metabotropic glutamate receptors. J. Comp. Neurol. 429, 270-276.

Reid, S. N., Romano, C., Hughes, T., and Daw,N.W.(1997). Developmental and sensory-dependent changes of phosphoinositide-linked metabotropic glutamate receptors. J. Comp. Neurol. 389, 577-583.

Reiff, D. F., Ihring, A., Guerrero, G., Isacoff, E. Y., Joesch, M., Nakai, J., and Borst, A. (2005). In vivo performance of genetically encoded indicators of neural activity in flies. J. Neurosci. 25 , 4766-4778.

Repicky, S., and Broadie, K. (2009). Metabotropic glutamate receptormediated use-dependent downregulation of synaptic excitability involves the fragile $\mathrm{X}$ mental retardation protein. J. Neurophysiol. 101, 672-687.

Restivo, L., Ferrari, F., Passino, E., Sgobio, C., Bock, J., Oostra, B. A., Bagni, C., and Ammassari-Teule, M. (2005). Enriched environment promotes behavioral and morphological recovery in a mouse model for the fragile X syndrome. Proc. Natl. Acad. Sci. U.S.A. 102, 11557-11562.

Rogers, S. J., Wehner, D. E., and Hagerman, R. (2001). The behavioral phenotype in fragile $\mathrm{X}$ : symptoms of autism in very young children with fragileX syndrome, idiopathic autism, and other developmental disorders. J. Dev. Behav. Pediatr. 22, 409-417.

Roy, B., Singh, A. P., Shetty, C., Chaudhary, V., North,A., Landgraf, M., Vijayraghavan, K., and Rodrigues, V. (2007). Metamorphosis of an identified serotonergic neuron in the Drosophila olfactory system. Neural Dev. 2, 20.

Rudelli, R.D., Brown, W.T., Wisniewski, K., Jenkins,E.C.,Laure-Kamionowska, M., Connell, F., and Wisniewski, H. M. (1985). Adult fragile X syndrome. Clinico-neuropathologic findings. Acta Neuropathol. 67, 289-295.

Sachse, S., Rueckert, E., Keller, A., Okada, R., Tanaka, N. K., Ito, K., and Vosshall, L. B. (2007). Activitydependent plasticity in an olfactory circuit. Neuron 56, 838-850.

Schroll, C., Riemensperger, T., Bucher, D., Ehmer, J., Voller, T., Erbguth, K., Gerber, B., Hendel, T., Nagel, G., Buchner, E., and Fiala, A. (2006). Light-induced activation of distinct modulatory neurons triggers appetitive or aversive learning in Drosophila larvae. Curr. Biol. 16, 1741-1747.

Schuster, S., Strauss, R., and Gotz, K. G. (2002). Virtual-reality techniques resolve the visual cues used by fruit flies to evaluate object distances. Curr. Biol. 12, 1591-1594.

Scott, E. K., Reuter, J. E., and Luo, L. (2003). Dendritic development of Drosophila high order visual system neurons is independent of sensory experience. BMC Neurosci. 4, 14.

Seid, M. A., and Wehner, R. (2009). Delayed axonal pruning in the ant brain: a study of developmental trajectories. Dev. Neurobiol. 69, 350-364.

Si, K., Lindquist, S., and Kandel, E. R. (2003). A neuronal isoform of the aplysia CPEB has prion-like properties. Cell 115, 879-891.

Sigrist, S. J., Thiel, P. R., Reiff, D. F., and Schuster, C. M. (2002). The postsynaptic glutamate receptor subunit DGluR-IIA mediates long-term plasticity in Drosophila. J. Neurosci. 22, 7362-7372.

Singh, K., Gaur, P., and Prasad, S. (2007). Fragile $\times$ mental retardation $($ Fmr-1) gene expression is down regulated in brain of mice during aging. Mol. Biol. Rep. 34, 173-181.

Siomi, M. C., Siomi, H., Sauer, W. H., Srinivasan, S., Nussbaum, R. L., and Dreyfuss, G. (1995). FXR1, an autosomal homolog of the fragile $\mathrm{X}$ mental retardation gene. $E M B O J .14$ 2401-2408.

Srahna, M., Leyssen, M., Choi, C. M., Fradkin, L. G., Noordermeer, J. N., and Hassan, B. A. (2006). A signaling network for patterning of neuronal connectivity in the Drosophila brain PLoS Biol. 4, e348.

Su, H., and O'Dowd, D. K. (2003). Fast synaptic currents in Drosophila mushroom body Kenyon cells are mediated by alpha-bungarotoxin-sensitive nicotinic acetylcholine receptors and picrotoxin-sensitive GABA receptors. J. Neurosci. 23, 9246-9253.

Sullivan, K., Hatton, D., Hammer, J. Sideris, J., Hooper, S., Ornstein, P., and Bailey, D., Jr. (2006). ADHD symptoms in children with FXS. Am J. Med. Genet. 140, 2275-2288.

Sweeney, S. T., Broadie, K., Keane, J., Niemann, H., and O'Kane, C. J. (1995). Targeted expression of tetanus toxin light chain in Drosophila specifically eliminates synaptic transmission and causes behavioral defects. Neuron 14 341-351.

Tessier, C. R., and Broadie, K. (2008). Drosophila fragile X mental retardation protein developmentally regulates activity-dependent axon pruning. Development 135, 1547-1557.

Todd, P. K., and Mack, K. J. (2000). Sensory stimulation increases cortical expression of the fragile $\mathrm{X}$ mental retardation protein in vivo. Brain Res. Mol. Brain Res. 80, 17-25.

Todd, P. K., Mack, K. J., and Malter, J. S. (2003). The fragile X mental retardation protein is required for type-I metabotropic glutamate receptor-dependent translation of PSD-95. Proc. Natl. Acad. Sci. U.S.A. 100, 14374-14378.

Tracey, W.D., Jr., Wilson, R. I., Laurent, G., and Benzer, S. (2003). Painless, a Drosophila gene essential for nociception. Cell 113, 261-273.
Tripodi, M., Evers, J. F., Mauss, A., Bate, M., and Landgraf, M. (2008). Structural homeostasis: compensatory adjustments of dendritic arbor geometry in response to variations of synaptic input. PLoS Biol. 6, e260.

Tully, T., Preat, T., Boynton, S. C., and Del Vecchio, M. (1994). Genetic dissection of consolidated memory in Drosophila. Cell 79, 35-47.

Tully, T., and Quinn, W.G. (1985).Classical conditioning and retention in normal and mutant Drosophila melanogaster. J. Comp. Physiol. 157, 263-277.

van der Bliek,A.M., and Meyerowitz, E. M. (1991).Dynamin-like protein encoded by the Drosophila shibire gene associated with vesicular traffic. Nature 351 , 411-414.

Vanderklish, P. W., and Edelman, G. M. (2002). Dendritic spines elongate after stimulation of group 1 metabotropic glutamate receptors in cultured hippocampal neurons. Proc. Natl. Acad. Sci. U.S.A. 99, 1639-1644.

Volk, L. J., Pfeiffer, B. E., Gibson, J. R. and Huber, K. M. (2007). Multiple Gq-coupled receptors converge on a common protein synthesis-dependent long-term depression that is affected in fragile $\mathrm{X}$ syndrome mental retardation. J. Neurosci. 27, 11624-11634.

Wan, L., Dockendorff, T. C., Jongens, T. A., and Dreyfuss, G. (2000). Characterization of dFMR1, a Drosophila melanogaster homolog of the fragile X mental retardation protein. Mol. Cell. Biol. 20, 8536-8547.

Wang, H., Ku, L., Osterhout, D. J., Li, W., Ahmadian, A., Liang, Z., and Feng, Y. (2004). Developmentallyprogrammed FMRP expression in oligodendrocytes: a potential role of FMRP in regulating translation in oligodendroglia progenitors. Hum. Mol. Genet. 13, 79-89.

Wang, H., Sugiyama, Y., Hikima, T., Sugano, E., Tomita, H., Takahashi, T., Ishizuka, T., and Yawo, H. (2009a). Molecular determinants differentiating photocurrent properties of two channelrhodopsins from chlamydomonas. J. Biol. Chem. 284, 5685-5696.

Wang, H., Wu, L. J., Zhang, F., and Zhuo, M. (2008). Roles of calciumstimulated adenylyl cyclase and calmodulin-dependent protein kinase IV in the regulation of FMRP by group I metabotropic glutamate receptors. J. Neurosci. 28, 4385-4397.

Wang, J. W., Wong, A. M., Flores, J., Vosshall, L. B., and Axel, R. (2003). Two-photon calcium imaging reveals an odor-evoked map of activity in the fly brain. Cell 112, 271-282.

Wang, Q., Chang, L., Rowan, M. J., and Anwyl, R. (2007). Developmental dependence, the role of the kinases $\mathrm{p} 38$ 
MAPK and PKC, and the involvement of tumor necrosis factor-R1 in the induction of mGlu-5 LTD in the dentate gyrus. Neuroscience 144, 110-118.

Wang, Y., Zheng, F., Zhou, X., Sun, Z., and Wang, H. (2009b). Converging signal on ERK1/2 activity regulates group I mGluR-mediated Arc transcription. Neurosci. Lett. 460, 36-40

Waung, M. W., Pfeiffer, B. E., Nosyreva, E. D., Ronesi, J. A., and Huber, K. M. (2008). Rapid translation of Arc/Arg3.1 selectively mediates mGluR-dependent LTD through persistent increases in AMPAR endocytosis rate. Neuron 59, 84-97.

White, B. H., Osterwalder, T. P., Yoon, K. S., Joiner, W. J., Whim, M. D., Kaczmarek, L. K., and Keshishian, H. (2001). Targeted attenuation of electrical activity in Drosophila using a genetically modified $\mathrm{K}(+)$ channel. Neuron 31, 699-711.

Wiesel, T. N. (1982). Postnatal development of the visual cortex and the influence of environment. Nature 299, 583-591.

Wijetunge, L. S., Till, S. M., Gillingwater, T. H., Ingham, C. A., and Kind, P. C. (2008). mGluR5 regulates glutamate-dependent development of the mouse somatosensory cortex. J. Neurosci. 28, 13028-13037.

Wilson, B. M., and Cox, C. L. (2007). Absence of metabotropic glutamate receptor-mediated plasticity in the neocortex of fragile X mice. Proc. Natl. Acad. Sci. U.S.A. 104, 2454-2459.

Wilson, R. I., and Laurent, G. (2005). Role of GABAergic inhibition in shaping odor-evoked spatiotemporal pat- terns in the Drosophila antennal lobe. J. Neurosci. 25, 9069-9079.

Wilson, R. I., Turner, G. C., and Laurent, G. (2004). Transformation of olfactory representations in the Drosophila antennal lobe. Science 303, 366-370.

Withers, G. S., Fahrbach, S. E., and Robinson, G. E. (1993). Selective neuroanatomical plasticity and division of labour in the honeybee. Nature 364, 238-240.

Wong, R. O., and Ghosh, A. (2002). Activity-dependent regulation of dendritic growth and patterning. Nat. Rev. 3, 803-812.

Xu, S. Y., Cang, C. L., Liu, X. F., Peng, Y. Q., Ye, Y. Z., Zhao, Z. Q., and Guo, A. K. (2006). Thermal nociception in adult Drosophila: behavioral characterization and the role of the painless gene. Genes Brain Behav. 5, 602-613.

Yates, P.A., Roskies, A. L., McLaughlin, T., andO'Leary,D.D.(2001).Topographicspecific axon branching controlled by ephrin-As is the critical event in retinotectal map development. J. Neurosci. 21, 8548-8563.

Yin, J. C., Wallach, J. S., Del Vecchio, M., Wilder, E. L., Zhou, H., Quinn, W. G., and Tully, T. (1994). Induction of a dominant negative CREB transgene specifically blocks long-term memory in Drosophila. Cell 79, 49-58.

Yu, C. R., Power, J., Barnea, G., O’Donnell, S., Brown, H. E., Osborne, J., Axel, R., and Gogos, J. A. (2004). Spontaneous neural activity is required for the establishment and maintenance of the olfactory sensory map. Neuron 42, 553-566.
Yu,D.,Akalal, D. B., and Davis, R. L. (2006). Drosophila alpha/beta mushroom body neurons form a branch-specific, long-term cellular memory trace after spaced olfactory conditioning. Neuron 52, 845-855.

Yu, D., Baird, G. S., Tsien, R. Y., and Davis, R. L. (2003). Detection of calcium transients in Drosophila mushroom body neurons with camgaroo reporters. J. Neurosci. 23, 64-72.

Yurkovic, A., Wang, O., Basu, A. C., and Kravitz, E. A. (2006). Learning and memory associated with aggression in Drosophila melanogaster. Proc. Natl. Acad. Sci. U.S.A. 103 17519-17524.

Zalfa, F., Eleuteri, B., Dickson, K. S. Mercaldo, V., De Rubeis, S., di Penta, A., Tabolacci, E., Chiurazzi, P., Neri, G., Grant, S. G., and Bagni, C. (2007). A new function for the fragile $\mathrm{X}$ mental retardation protein in regulation of PSD-95 mRNA stability. Nat Neurosci. 10, 578-587.

Zhang, J., Hou, L., Klann, E., and Nelson, D. L. (2009). Altered hippocampal synaptic plasticity in the FMR1 gene family knockout mouse models. J. Neurophysiol. 101, 2572-2580.

Zhang, W., Ge, W., and Wang, Z (2007). A toolbox for light control of Drosophila behaviors through Channelrhodopsin 2-mediated photoactivation of targeted neurons. Eur. J. Neurosci. 26, 2405-2416.

Zhang, Y., O'Connor, J. P., Siomi, M. C., Srinivasan, S., Dutra, A., Nussbaum, R. L., and Dreyfuss, G. (1995). The fragile X mental retardation syndrome protein interacts with novel homologs FXR1 and FXR2. EMBO J. 14, 5358-5366.

Zhang, Y. Q., Bailey, A. M., Matthies, H. J., Renden, R. B.,Smith,M.A.,Speese, S. D. Rubin, G. M., and Broadie, K. (2001). Drosophila fragile X-related gene regulates the MAP1B homolog Futsch to control synaptic structure and function. Cell 107, 591-603.

Zhang, Y. Q., and Broadie, K. (2005). Fathoming fragile $\mathrm{X}$ in fruit flies. Trends Genet. 21, 37-45.

Zheng, C., Feinstein, P., Bozza, T., Rodriguez, I., and Mombaerts, P. (2000). Peripheral olfactory projections are differentially affected in mice deficient in a cyclic nucleotide-gated channel subunit. Neuron 26, 81-91.

Conflict of Interest Statement: The authors declare that the research was conducted in the absence of any commercial or financial relationships that could be construed as a potential conflict of interest.

Received: 08 June 2009; paper pending published: 09 July 2009; accepted: 15 July 2009; published online: 30 July 2009. Citation: Tessier CR and Broadie K (2009) Activity-dependent modulation of neural circuit synaptic connectivity. Front. Mol. Neurosci. 2:8. doi: 10.3389/neuro.02.008.2009

Copyright @ 2009 Tessier and Broadie. This is an open-access article subject to an exclusive license agreement between the authors and the Frontiers Research Foundation, which permits unrestricted use, distribution, and reproduction in any medium, provided the original authors and source are credited. 